\title{
Las causas de resolución de los contratos administrativos en la nueva Ley de Contratos del Sector Público de 2017
}

\author{
Concepción Barrero Rodríguez \\ Universidad de Sevilla \\ barrero@us.es
}

\begin{abstract}
NOTA BIOGRÁFICA
Catedrática de Derecho Administrativo de la Universidad de Sevilla. Entre sus líneas de investigación se encuentran la contratación pública, el procedimiento administrativo, el régimen local o el Derecho del Patrimonio Histórico.
\end{abstract}

\section{SUMARIO}

I. CONSIDERACIONES INICIALES. II. EL RÉGIMEN GENERAL DE LA RESOLUCIÓN. 1. LAS CAUSAS DE RESOLUCIÓN. 1.1. LA DEMORA POR EL CONTRATISTA EN LA EJECUCIÓN DEL CONTRATO. 1.2. EL INCUMPLIMIENTO POR EL CONTRATISTA DE SUS OBLIGACIONES CONTRACTUALES. 1.3. LA RESOLUCIÓN DERIVADA DE LA MODIFICACIÓN DEL CONTRATO. 1.4. EL INCUMPLIMIENTO POR EL CONTRATISTA DE SUS OBLIGACIONES LABORALES. 2. LA APLICACIÓN DE LAS CAUSAS DE RESOLUCIÓN. 2.1. LAS DISPOSICIONES GENERALES. 2.2. LAS NORMAS CONCRETAS SOBRE LA APLICACIÓN DE LAS DIFERENTES CAUSAS DE RESOLUCIÓN. 2.2.1. La resolución derivada de la potestad de modificación del contrato. 2.2.2. La resolución con origen en una declaración de concurso. 3. LOS EFECTOS DE LA RESOLUCIÓN. 3.1. LAS PREVISIONES DE CARÁCTER GENERAL. 3.2. LOS EFECTOS CONCRETOS DE ALGUNAS CAUSAS DE RESOLUCIÓN. 3.2.1. Las consecuencias de la resolución por incumplimiento culpable del contratista. 3.2.2. Los efectos de una resolución ligada a la modificación del contrato. 3.3. LA INSUFICIENCIA DEL ARTÍCULO 213 DE LA LCSP EN RELACIÓN CON ALGUNAS CAUSAS DE RESOLUCIÓN. 3.3.1. Consideraciones generales. 3.3.2. La resolución por concurso del contratista. 3.3.3. La ruptura del contrato por la causa prevista en el artículo 211.1 i). III. LAS CAUSAS PROPIAS DE RESOLUCIÓN DE CADA CONTRATO. 1. EL CONTRATO DE OBRAS. 2. EL CONTRATO DE CONCESIÓN DE OBRA PÚBLICA. 3. EL CONTRATO DE CONCESIÓN DE SERVICIOS. 4. EL CONTRATO DE SUMINISTRO. 5. EL CONTRATO DE SERVICIOS.

\section{CONSIDERACIONES INICIALES}

La Ley 9/2017, de 8 de noviembre, de Contratos del Sector Público, por la que se transponen al ordenamiento jurídico español las Directivas del Parlamento Europeo y del Consejo 2014/23/UE y 2014/24/UE, de 26 de febrero de 2014 (LCSP) establece que «los contratos se extinguirán por su cumplimiento o por resolución». La norma no define sin embargo, en lo que sigue una importante tradición histórica, este último modo de conclusión de la relación contractual, ante lo que es preciso acudir al concepto civil de la institución, desde el que puede afirmarse, y ello es válido también para el Derecho Administrativo, que la resolución supone la ruptura anticipada del contrato antes del transcurso del plazo previsto para su ejecución y sin la completa realización de su objeto ${ }^{1}$.

Las razones que llevan a esa disolución del vínculo contractual pueden ser muy variadas. Nuestro ordenamiento jurídico, y así lo hace también la Ley de 2017, las ha sistematizado siempre a partir de su

\footnotetext{
1 Al respecto puede verse C. BARRERO RODRÍGUEZ, La resolución de los contratos administrativos por incumplimiento del contratista, 2. ${ }^{\text {a }}$ ed., Lex Nova, Valladolid, 2011.
} 
diferenciación entre causas generales y causas propias de los diversos contratos que regula, distinción de la que nos valemos en este estudio cuyo objeto no es otro que el dar cuenta de las innovaciones introducidas en esta materia por la nueva LCSP, prescindiendo, por consiguiente, del análisis de aquellas causas cuya regulación no ha sufrido variación respecto de la establecida en el Texto Refundido de Contratos del sector público aprobado por el RDLeg. 3/2011, de 14 de noviembre (TRCSP).

\section{EL RÉGIMEN GENERAL DE LA RESOLUCIÓN}

La LCSP distingue, y así también lo haremos nosotros, entre causas de resolución, su aplicación y la determinación de sus efectos, objeto de tratamiento en sus artículos 211, 212 y 213, respectivamente. Una regulación aplicable exclusivamente a los contratos administrativos con la excepción de la causa prevista en el artículo 211.1.g) que, como determina el 26.3, abarca también a «los contratos privados que celebren los poderes adjudicadores que no pertenezcan a la categoría de Administraciones Públicas... cuyo objeto esté comprendido en el ámbito de la presente Ley».

\section{Las causas de resolución}

Con carácter general e introductorio, cabe destacar que el artículo 211 LCSP ha establecido una nueva causa general de resolución de los contratos administrativos: el incumplimiento de determinadas obligaciones laborales por parte del contratista, y ha modificado algunas de las ya existentes en el ordenamiento precedente: las relativas a la demora en el plazo de ejecución del contrato, el incumplimiento por el contratista de sus obligaciones contractuales y el ejercicio por la Administración de su potestad de modificación del contrato. En otros casos, la LCSP mantiene sin alteración causas procedentes del Derecho anterior. Así sucede con «la muerte o incapacidad sobrevenida del contratista individual o la extinción de la personalidad jurídica de la sociedad contratista», la «declaración de concurso o la declaración de insolvencia en cualquier otro procedimiento», "el mutuo acuerdo entre la Administración y el contratista» y «las que se señalen específicamente para cada categoría de contrato», determinadas, respectivamente, en las letras a), b), c) y h) del artículo 211.1. Finalmente, suprime la tradicional cláusula residual, presente hasta ahora en nuestras disposiciones sobre contratación pública, que declaraba causa de resolución «las establecidas expresamente en el contrato».

Centramos nuestra atención en aquéllas en las que la LCSP aporta alguna novedad en relación con lo dispuesto por el TRCSP.

\subsection{La demora por el contratista en la ejecución del contrato}

El incumplimiento por el contratista del plazo contractual ha figurado siempre entre las causas generales de resolución de los contratos administrativos, expresión de la trascendencia que para la satisfacción de los intereses públicos tiene la ejecución del contrato en el tiempo inicialmente previsto. El artículo 193.1 de la LCSP establece, en términos tomados de normas anteriores, la obligación del contratista de «cumplir el contrato dentro del plazo total fijado para la realización del mismo, así como de los plazos parciales señalados para su ejecución sucesiva». El artículo 211.1.d), en consonancia con ello, considera «la demora en el cumplimiento de los plazos...» causa de resolución. Ahora bien, la mera infracción del plazo contractual no constituye, nunca lo ha sido, motivo de ruptura del contrato. Este es un resultado que nuestro ordenamiento ha reservado tradicionalmente, y así lo recogen hoy los artículos 192.2 y 193.3 de la LCSP, a los supuestos en los que obedezca a "causas imputables al contratista». De no ser así, y siempre que ofrezca "cumplir sus compromisos si se le amplía el plazo inicial de ejecución», el órgano de contratación, artículo 195.2, deberá concederle la ampliación que «será, por lo menos, igual al tiempo perdido», a no ser que «pidiese otro menor». Tampoco el incumplimiento imputable al contratista determina inexorablemente la resolución del contrato. Simplemente faculta a la Administración para poder acordarla «atendidas las circunstancias del caso», aunque puede optar también por su continuidad con la imposición de las correspondientes penalidades en las cuantías y términos establecidos en el artículo 193.

Ahora bien, esta regla general, y única en nuestro ordenamiento hasta ahora, se excepciona por el artículo 211.1.d) de la LCSP en los supuestos de «retraso injustificado sobre el plan de trabajos establecido 
en el pliego o en el contrato, en cualquier actividad, por un plazo superior a un tercio del plazo de duración inicial del contrato, incluidas las posibles prórrogas». Unos supuestos que, «en todo caso», determinan la resolución del contrato. Con esta previsión, introducida en la Ley por el Congreso de los Diputados², la Administración, ante un incumplimiento de estas características imputable al contratista, así ha de calificarse «el retraso injustificado» al que se refiere la norma, queda privada de la capacidad con la que siempre ha contado, y de la que sigue disponiendo fuera de estas concretas hipótesis, para decidir entre la ruptura o no del contrato que necesariamente deberá resolverse.

\subsection{El incumplimiento por el contratista de sus obligaciones contractuales}

La LCSP ha modificado, al igual que hicieron las disposiciones que la han precedido, esta causa de resolución del contrato. Así, su artículo 211.1.f) considera, ante todo, motivo posible de ruptura de la relación contractual el incumplimiento por el contratista de «la obligación principal del contrato» que, en principio, cabe identificar con la prestación que constituya su objeto. Con esta previsión, que carece de antecedentes en normas anteriores, la LCSP resuelve, como manifestó el Consejo de Estado en su Dictamen 1116/2015, de 10 de marzo de 2016, al Anteproyecto de Ley, «la dificultad interpretativa» que planteaba el TRCSP en los casos en los que los pliegos declaraban «esenciales varias de las obligaciones accesorias imputables al contratista», pero omitían, sin embrago, esa «calificación en lo que atañe al objeto mismo del contrato (la realización de la obra, la entrega del suministro o la prestación del servicio) por su obviedad».

El artículo 211.1.f) establece también, en segundo lugar, que el contrato puede resolverse ante el incumplimiento por el contratista «de las restantes obligaciones esenciales siempre que éstas últimas hubiesen sido calificadas como tales en los Pliegos o en el correspondiente documento técnico descriptivo» ${ }^{3}$. Una cláusula procedente del artículo 223.f) del TRCSP a la que se incorporan, no obstante, dos exigencias inexistentes en esta norma: 1) Que la delimitación efectuada respete «los límites que el apartado 1 del artículo 34 establece para la libertad de pactos», esto es, que no sea contraria «al interés público, al ordenamiento jurídico y a los principios de buena administración»; y 2) Que tales obligaciones «figuren enumeradas de manera precisa, clara e inequívoca en los pliegos o en el documento descriptivo, no siendo admisibles cláusulas de tipo general». Unas exigencias con las que LCSP, en opinión del Consejo de Estado expresada en ese mismo dictamen, trata de impedir que el pliego del contrato «configure como obligaciones esenciales cuyo incumplimiento determine la resolución contractual todas las obligaciones asumidas por el contratista». No hace falta pues insistir en la importancia de que estos documentos definan las obligaciones de estas características, importancia que, como manifestó igualmente ese órgano consultivo, se ve hoy reforzada por el hecho de que el artículo 211.1, a diferencia de las Leyes precedentes, no contiene ya una remisión genérica a otras posibles causas de resolución «establecidas expresamente en el contrato», lo que supone que para que «este efecto extintivo pueda modularse en función de las características propias de cada contrato, la única opción remanente será la definición en el pliego de dichas obligaciones esenciales, lo que habrá de tenerse en cuenta en la confección del mismo».

Cabe esperar que los nuevos requisitos de tipificación de las obligaciones contractuales introducidos por la Ley pongan fin, o al menos reduzcan, los problemas interpretativos planteados por la Ley 30/2007, de 30 de octubre, de Contratos del sector público y su Texto Refundido en el extremo relativo a la capacidad de la entidad contratante para resolver un contrato ante el incumplimiento de obligaciones no calificadas como esenciales en los pliegos pero que pudieran revestir tal carácter de acuerdo con la normativa reguladora del contrato ${ }^{4}$. No obstante, no cabe excluir, aunque con menor incidencia desde luego que antes, que puedan,

\footnotetext{
2 El Informe de la Ponencia manifiesta que el nuevo texto es «consecuencia de la aceptación de la enmienda transaccional procedente de la enmienda 388 del GP Ciudadanos» que pedía, en efecto, incorporar esa causa de resolución con la justificación de que así se «otorga una mayor seguridad a la administración del buen término del contrato, ...».

Las enmiendas se encuentran publicadas en el Boletín Oficial de las Cortes Generales, Congreso de los Diputados, XII Legislatura, Serie A, Proyectos de Ley, núm. 2-2, 16 de marzo de 2017 y el Informe de la Ponencia en Boletín Oficial de las Cortes Generales, Congreso de los Diputados, XII Legislatura, Serie A, Proyectos de Ley, núm. 2-4, 2 de agosto de 2017.

${ }_{3}$ Cabe recordar que fue de la Ley 13/1995, de 18 de mayo, de Contratos de las Administraciones Públicas la que en su artículo 112.g), estableció, recogiendo el criterio mantenido por el Consejo de Estado y la jurisprudencia en su interpretación de la normativa anterior -artículos 65 del Reglamento de Contratación de las Corporaciones Locales de 1953 y 52.1 y 75.1 de la Ley de Contratos de 1965- el carácter «esencial» de la obligación cuyo incumplimiento por el contratista faculta a la Administración para resolver el contrato.

${ }^{4}$ Su previsión, sin mayor especificación, de que es causa de resolución «el incumplimiento de las obligaciones que estén calificadas, como tales, en los pliegos o en el contrato» va, en efecto, a dividir a los órganos consultivos en su respuesta a esta cuestión, aunque finalmente se impondrá la tesis favorable a la posible ruptura del contrato en estos supuestos. Una interpretación que, según
} 
en determinadas ocasiones, seguir suscitándose dudas al respecto. Habrá que estar atentos a la interpretación que puedan ofrecer sobre el particular los órganos consultivos y la jurisprudencia.

\subsection{La resolución derivada de la modificación del contrato}

La LCSP establece una regulación de la modificación de los contratos que parte de la diferenciación introducida en nuestro ordenamiento por la Ley 2/2011, de 4 de marzo, de Economía sostenible, entre modificaciones pactadas y modificaciones que operan ex lege. Así su artículo 203.2 determina que los contratos solo podrán modificarse «cuando así se haya establecido en el pliego de cláusulas administrativas particulares» en los términos previstos en el artículo 204, o «excepcionalmente, cuando sea necesario realizar una modificación que no esté prevista en el pliego de cláusulas administrativas particulares siempre y cuando se cumplan las condiciones que establece el artículo 205»; precepto que incorpora el conjunto de circunstancias que, de acuerdo con el artículo 72 la Directiva 2014/24, hacen posible la variación del contrato sin necesidad de acudir a una nueva licitación. Fuera de estos supuestos, añade el artículo 203.2, «si fuese necesario que un contrato en vigor se ejecutase en forma distinta a la pactada, deberá procederse a su resolución y a la celebración de otro bajo las condiciones pertinentes, ...». En coherencia con esta previsión, el artículo 211.1.g) considera causa general de resolución «la imposibilidad de ejecutar la prestación en los términos inicialmente pactados, cuando no sea posible modificar el contrato conforme a los artículos 204 y 205».

Ahora bien, el artículo 211.1.g), y aquí radica su novedad en relación con lo establecido en el TRCSP, prevé también la resolución del contrato «cuando dándose las circunstancias establecidas en el artículo $205 »$, esto es siendo posible su variación, «las modificaciones impliquen, aislada o conjuntamente, alteraciones del precio del mismo, en cuantía superior, en más o en menos, al 20 por ciento del precio inicial del contrato, con exclusión del Impuesto sobre el Valor Añadido». El artículo 206.1 declara obligatorias para el contratista las modificaciones impuestas por la Ley que no excedan de esta cuantía. Si la supera, requiere su «previa conformidad por escrito», resolviéndose «el contrato, en caso contrario». De esta forma, la LCSP recupera un supuesto de resolución previsto para el contrato de obras en el ordenamiento anterior y que la Ley de Economía Sostenible había eliminado ${ }^{5}$, recuperación que el dictamen del Consejo de Estado al Anteproyecto de Ley sitúo entre las reformas del régimen de resolución que «resultan acertadas».

\subsection{El incumplimiento por el contratista de sus obligaciones laborales}

El artículo 211.1.i) de la LCSP, sin precedente alguno en nuestro ordenamiento, establece como causa de resolución «el impago, durante la ejecución del contrato, de los salarios por parte del contratista a los trabajadores que estuvieran participando en la misma, o el incumplimiento de las condiciones establecidas en los Convenios colectivos en vigor para estos trabajadores también durante la ejecución del contrato».

Con la previsión de este motivo de ruptura del contrato, que se introduce por el Congreso de los Diputados que acepta diversas enmiendas presentadas con tal fin ${ }^{6}$, la resolución se desvincula del incumplimiento

concluye el Consejo de Estado en su Dictamen 47/2016, de 23 de diciembre, «trata de evitar un rigorismo literalista que impida el ejercicio de la potestad administrativa de resolución cuando los incumplimientos sean materialmente esenciales, ya que la voluntad evidente del legislador es incentivar el celo de los redactores de los documentos de contratación y moderar el empleo de la potestad de resolución, pero no impedirla en casos de incumplimientos groseros y flagrantes o que demuestren una voluntad del contratista rebelde al cumplimiento».

5 Véanse artículos 150.e) de la Ley Contratos de 1995 y 220.e) de la Ley de Contratos del Sector Público de 2007 antes de su modificación por la Ley de 2/2011, de Economía Sostenible.

${ }^{6}$ Así en el Informe de la Ponencia puede leerse que ésta «ha aprobado por unanimidad un nuevo texto en relación con este artículo..., como consecuencia de la aceptación de la enmienda transaccional procedente de las enmiendas 147 del GP Confederal de Unidos Podemos-En Comú Podem-En Marea, 297 y 306 del GP de Esquerra Republicana, 676 del Grupo Parlamentario Socialista y 917 del GP Mixto-PDeCAT».

El primero de estos Grupos parlamentarios había propuesto que fuera causa de resolución «el impago de los salarios por parte del adjudicatario a la plantilla que participa de la ejecución del contrato o el incumplimiento de las condiciones establecidas en los convenios colectivos en vigor durante su ejecución». Por su parte, los Grupos de «Ezquerra Republicana», «Socialista» y «Mixto» solicitaban incluir como motivo de resolución «los incumplimientos o los retrasos reiterados en el pago de los salarios, o la aplicación de condiciones salariales inferiores a las derivadas de los convenios colectivos que sea grave y dolosa». En su justificación, la enmienda 147 señalaba que «el incumplimiento de la legislación en materia laboral debe ser un motivo básico de resolución de un contrato puesto que la Administración no puede permitir que existan trabajadores que prestan servicios públicos y cobren sus salarios de manera regular, mientras que otros, que también participan en la prestación de servicios públicos aunque sea a través de la forma de gestión 
de las obligaciones derivadas del propio contrato, ámbito al que tradicionalmente había estado circunscrita, para alcanzar a la infracción por el contratista de otros deberes al margen de la relación contractual, como son los impuestos por la normativa laboral ${ }^{7}$. Más adelante tendremos oportunidad de comprobar como la introducción de este motivo de ruptura de la relación contractual, cuya conveniencia no se cuestiona, no ha ido acompañada de un régimen que garantice su efectiva aplicación, lo que hace dudar de su eficacia. Habrá, no obstante, que esperar a que transcurra cierto tiempo para comprobar su grado de aplicación y valorar la interpretación que, en su caso, puedan ofrecernos las diferentes instancias consultivas y la jurisprudencia contencioso-administrativa.

\section{La aplicación de las causas de resolución}

El artículo 212 de la LCSP regula la «aplicación de las causas de resolución». En él puede diferenciarse entre normas aplicables a todas ellas y normas referidas específicamente a concretas causas de resolución del precepto anterior. Analizamos separadamente unas y otras.

\subsection{Las disposiciones generales}

La resolución del contrato se ha de acordar, como determina su apartado $1 .^{\circ}$, por «el órgano de contratación, de oficio o a instancias del contratista, en su caso, siguiendo el procedimiento que en las normas de desarrollo de esta Ley se establezca». Esta regla se excepciona, por el propio precepto, en los supuestos en los que la causa de resolución sea la prevista en el artículo 211.1.i), en cuyo caso, "solo se acordará, con carácter general, a instancia de los representantes de los trabajadores en la empresa contratista», lo que supone que la capacidad de instar el procedimiento de resolución contractual escapa a las partes contratantes, las únicas que pueden hacerlo respecto del resto de las causas, dejando en manos de los propios trabajadores la decisión sobre la continuidad del contrato. Una regla que, a su vez, se excluye «cuando los trabajadores afectados por el impago de salarios sean trabajadores en los que procediera la subrogación de conformidad con el artículo 130 y el importe de los salarios adeudados por la empresa contratista supere el 5 por ciento del precio de adjudicación del contrato, en cuyo caso podrá ser acordada directamente por el órgano de contratación de oficio».

Aunque el procedimiento de resolución queda remitido a norma reglamentaria, el artículo 191 de la LCSP establece, al igual que las Leyes anteriores, dos trámites de obligado cumplimiento: la audiencia al contratista y «el dictamen del Consejo de Estado u órgano equivalente de la Comunidad Autónoma respectiva» cuando «se formule oposición» por su parte. En espera del anunciado desarrollo reglamentario, el procedimiento aplicable será el previsto en el RD 1098/2001, de 12 de octubre, del Reglamento general de la Ley de Contratos de las Administraciones Públicas (RGCAP), en vigor en lo que no se oponga a las nuevas disposiciones legales. Con carácter supletorio se aplicará, como determina la disposición final 2. ${ }^{ } .1$ de la LCSP, la Ley 39/2015, de 1 de octubre, del Procedimiento administrativo común (LPAC).

El artículo 212.8, lo que no hacían las disposiciones precedentes en materia de contratación, determina el plazo máximo en el que estos procedimientos «deberán ser instruidos y resueltos», ocho meses, a contar, como establece el artículo 21.3 de la LPAC, desde «la fecha del acuerdo de iniciación» en el caso de incoarse el procedimiento de oficio, o desde que la solicitud «haya tenido entrada en el registro electrónico de la Administración u Organismo competente para su tramitación» en los supuestos en los que sea el contratista el que con su petición da lugar a la apertura del procedimiento. Se trataba, sin duda, de una previsión necesaria dado que, ante la ausencia de un plazo específico, se venía aplicando el supletorio de tres meses previsto en la norma común del procedimiento administrativo, a todas luces insuficiente, como manifestaban los distintos órganos consultivos, ante la complejidad que, por lo general, muestran estos procedimientos ${ }^{8}$. La

indirecta, no lo hagan"; la 297 se refería a una «mejora técnica para garantizar el debido cumplimiento de las obligaciones laborales de los contratistas y subcontratistas»; y la 917 a que «esta cláusula permite garantizar la negociación colectiva y la capacidad de asumir incrementos tributarios o de las cotizaciones de seguridad social no previstos en la momento de la adjudicación».

7 M. RUÍZ DAIMIEL ha reflexionado sobre las dudas interpretativas que se suscitan en la conexión entre dos relaciones jurídicas, en principio independientes, como son la que unen al contratista, de una parte, con la Administración y, de otra, con sus trabajadores ("Los incumplimientos de las obligaciones laborales por el contratista de determinados servicios", Observatorio de la Contratación Pública, Sección Opinión).

${ }^{8}$ En tal sentido, Dictámenes, entre otros, del Consejo de Estado 690/2015, de 27 de julio, o 750/2016, de 10 de noviembre. 
falta de resolución y notificación en plazo determina, si el procedimiento se inició a instancias del contratista, que «podrá considerar desestimada su solicitud por silencio administrativo, sin perjuicio de la subsistencia de la obligación de resolver» de conformidad con lo dispuesto en la disposición final 2. ${ }^{a} .1$ de la LCSP. De haberse incoado de oficio, se producirá, como reconocen una consolidada doctrina de los órganos consultivos y la propia jurisprudencia, su caducidad y el consiguiente archivo de las actuaciones ${ }^{9}$.

Con carácter general igualmente, aunque en un plano muy diferente, debe significarse que ante la presencia de una causa de resolución las partes disponen de la facultad de optar entre el ejercicio de su potestad resolutoria o el mantenimiento del contrato, a excepción de aquellos supuestos en los que la propia norma impone su extinción, que es lo que ocurre, por disposición del artículo 112.2, ante «la declaración de insolvencia en cualquier procedimiento del contratista» y "las modificaciones del contrato en los casos en los que se den las circunstancias establecidas en los artículos 204 y 205». Llama la atención la falta de mención del precepto al tercero de los supuestos que, a tenor de lo establecido en el artículo 211.1.d), provoca igualmente la ruptura necesaria del contrato: «el retraso injustificado sobre el plan de trabajos establecido en el pliego o en el contrato, en cualquier actividad, por un plazo superior a un tercio del plazo de duración inicial del contrato, incluidas las posibles prórrogas». Un supuesto que, por consiguiente, tendría que haber figurado también en el artículo 212.2 entre aquéllos que «darán siempre lugar a la resolución del contrato». En todo caso, y aunque esta omisión pudiera generar alguna confusión, ante un incumplimiento del plazo de las características previstas en ese precepto procede la ruptura del contrato, lo que, sin duda, constituye una importante novedad en nuestro ordenamiento.

Entre las causas generales de resolución con origen, de otra parte, en la entidad contratante no existe ninguna que, de acuerdo con el artículo 212.7: «el incumplimiento de las obligaciones derivadas del contrato por parte de la Administración originará la resolución de aquel solo en los casos previstos en esta Ley», pueda determinar esta consecuencia.

Finalmente, cabe destacar que la LCSP positiviza en su 211.2 la regla, plenamente asentada en la doctrina de los órganos consultivos y en la jurisprudencia, que ante la presencia de «diversas causas de resolución del contrato con diferentes efectos en cuanto a las consecuencias económicas de la extinción», dispone que «deberá atenderse a la que haya aparecido con prioridad en el tiempo» ${ }^{10}$.

\subsection{Las normas concretas sobre la aplicación de las diferentes causas de resolución}

El artículo 212 de la LCSP completa sus previsiones generales en la materia con una serie de reglas particulares. Detendré mi atención en aquéllas en las que la nueva regulación ofrece variaciones respecto de la existente en el TRCSP de 2011. Prescindo pues del análisis de los supuestos en los que la causa de resolución sea «la muerte o incapacidad sobrevenida del contratista individual», respecto de la que el artículo 212.3 mantiene la regla tradicional en nuestro Derecho que permite a la Administración «acordar la continuidad del contrato con sus herederos o sucesores»" ${ }^{11}$, así como de las resoluciones basadas en el mutuo acuerdo entre la Administración y el contratista que «solo podrá tener lugar», como dispone el apartado $4 .^{\circ}$ del precepto reproduciendo igualmente una norma procedente de Leyes anteriores, "cuando no concurra otra causa de resolución que sea imputable al contratista, y siempre que razones de interés público hagan innecesaria o inconveniente la permanencia del contrato» ${ }^{12}$.

9 Como establece el Consejo de Estado, Dictamen, por ejemplo, 363/2017, de 29 de junio, y puede comprobarse en las recientes Sentencias del Tribunal Superior de Justicia de Murcia de 15 de diciembre de 2016 (JUR 2017/43612) o de Castilla y León, Sala de Valladolid, de 16 de diciembre de 2016 (JUR 2017/16054) que dan cuenta además de la posición del Tribunal Supremo en la materia.

10 La redacción final de este artículo es la sugerida por el Consejo de Estado en su Dictamen 1116/2015, de 10 de marzo de 2016 , que la consideraba más clara que la establecida en el texto sometido a su consideración, que señalaba que «cuando en una misma relación contractual concurrieran varias causas de las enumeradas en el apartado anterior, el órgano de contratación deberá estar a lo que resulte de la prioridad cronológica en su aparición». La redacción propuesta por el órgano consultivo coincide con su doctrina tradicional en la materia. Ya en su Dictamen número 47.892 de 4 de julio de 1985, frecuentemente citado a partir de esa fecha, había señalado que esa regla de prioridad tiene sentido «cuando concurren diversas causas de resolución del contrato con diferentes efectos en cuanto a las consecuencias económicas», toda vez que, si como indica el Dictamen 985/2014, de 4 de diciembre, éstas «son idénticas», procede «resolver el contrato por cualquiera de ellas».

11 EI RGCAP dispone en su artículo 110 que el acuerdo sobre la continuidad del contrato «será adoptado por el órgano de contratación a petición de los herederos o del representante del incapaz».

${ }_{12}$ Se trata de unas exigencias mantenidas con todo rigor por los órganos consultivos en aplicación de las disposiciones de igual contenido de las Leyes anteriores, como puede comprobarse, por ejemplo, en el Dictamen del Consejo de Estado 178/2016, de 31 


\subsubsection{La resolución derivada de la potestad de modificación del contrato}

El artículo 212.2 de la LCSP diferencia entre una resolución del contrato de aplicación necesaria, la que aparece en los supuestos en los que no sea posible modificarlo al no concurrir las circunstancias que lo hacen posible de conformidad con los artículos 204 y 205; y una segunda, inexistente en el TRCSP tras su modificación por la Ley de Economía Sostenible, de ejercicio potestativo tanto para la Administración como para el contratista, que surge en los casos en los que las modificaciones producidas «impliquen aislada 0 conjuntamente, una alteración en cuantía que exceda del 20 por ciento del precio inicial del contrato, IVA excluido».

\subsubsection{La resolución con origen en una declaración de concurso}

«En caso de declaración de concurso la Administración potestativamente continuará el contrato si razones de interés público así lo aconsejan, y siempre y cuando el contratista prestare las garantías adicionales suficientes a juicio de aquélla para su ejecución». Con esta norma, el artículo 212.5 de la LCSP modifica la regla establecida en el artículo 224.4 del TRCSP procedente, a su vez, del de 2000 tras su modificación por la Ley 22/2003, de 9 de julio, Concursal ${ }^{13}$, que determinaba que la apertura de la fase de liquidación del concurso daba «siempre lugar a la resolución». Una causa automática de ruptura del contrato que ahora parece que desaparece para, en el sentido apuntado por la doctrina ${ }^{14}$, dejar, en todo caso, en manos de la Administración contratante su posible continuidad. Interesa significar, no obstante, que en la reforma del precepto por el Congreso de los Diputados, consecuencia de la aceptación de una enmienda presentada por el Grupo Parlamentario Socialista, se eliminó la previsión del Proyecto de Ley que expresamente reconocía la posibilidad de la Administración de continuar en el contrato «aun cuando ya se hubiera producido la apertura de la fase de liquidación ${ }^{15}$. Su desaparición no impide, sin embargo, mantener que la apertura de dicha fase no obliga ya necesariamente a la ruptura del contrato. El tenor literal del artículo 212.5: «en caso de declaración en concurso la Administración potestativamente continuará el contrato...» y el hecho de que la regla general en nuestro ordenamiento sea la de la posible pervivencia del contrato incurso en una causa de resolución a menos que la norma disponga expresamente lo contrario, permiten entender, en espera de lo que en su caso puedan determinar los órganos consultivos y, en último término los tribunales, que la entidad contratante cuenta con la capacidad de mantener el contrato con el contratista declarado en concurso, aun abierta la fase de liquidación.

La decisión de la Administración sobre la continuidad o no del contrato se deberá adoptar, como también dispone el artículo 212.5 , atendiendo a las «razones de interés público» concurrentes en cada caso y a sí las garantías adicionales prestadas por el contratista son «suficientes para su ejecución». La LCSP, lo que no hacía la disposición precedente, concreta, tras la modificación introducida en el precepto en su tramitación parlamentaria ${ }^{16}$, qué garantías adicionales, exigencia que igualmente se introduce ahora, cuentan, en todo

de marzo, o en los Dictámenes 3/2014, de 10 de febrero del Consejo de Navarra; 223/2014, de 21 de julio, del Consejo jurídico de la Región de Murcia; 458/2014, de 16 de octubre del Consejo Consultivo de Castilla y León; 43/2015, de 5 de marzo, del Consejo consultivo del Principado de Asturias; 18/2016, de 27 de junio del Consejo consultivo de La Rioja; o 310/2016, de 11 de mayo del Consejo consultivo de Andalucía.

${ }_{13}$ En su redacción originaria, el artículo 212.2 de ese Texto Refundido disponía que «la declaración de quiebra, de concurso de acreedores, de insolvente o de fallido en cualquier procedimiento originará siempre la resolución del contrato».

14 I. DEL GUAYO CASTIELLA, Contratos del sector público y concurso de acreedores, La Ley, Madrid, 2011, págs. 93-95.

15 Cabe notar que este Grupo parlamentario (enmienda número 677) proponía que la Ley estableciera que la apertura de esa fase diera «lugar a la resolución automática del contrato» porque «la protección del interés público parece exigir que con la liquidación deban resolverse los contratos. En definitiva, si quien contrata con la Administración debe generar en todo momento confianza ésta no existe ni puede existir cuando se ha producido la apertura de la fase de liquidación cuya finalidad es la extinción del ente societario». La petición no fue atendida pero, sin embargo, se suprimió la previsión que reconocía expresamente la posibilidad de la Administración de mantenerse en los contratos aún abierta la fase de liquidación, y que había servido al Consejo de Estado para señalar en su dictamen al Anteproyecto de Ley que la norma en proyecto consumaba una «evolución legislativa tendente a privar de automatismo a la resolución de los contratos administrativos a raíz de concursos de acreedores». El propio órgano consultivo dejaba apuntadas «las condiciones extraordinarias que han de concurrir para que sea factible la pervivencia del vínculo contractual que une a la Administración con una sociedad en liquidación».

${ }^{16}$ La modificación del entonces artículo 209 es, como indica el Informe de la Ponencia, «consecuencia de la aceptación de la enmienda transaccional procedente de la enmienda 677 del GP Socialista», enmienda que también proponía, lo que sin embargo no fue aceptado, que se considerase «garantía suficiente» la «aprobación judicial del plan de viabilidad que acompañe la propuesta convenio cuando se prevea -para atender al cumplimiento del convenio- contar con los recursos que genere la continuación en el ejercicio de la 
caso, con esa condición de «suficientes» que la Ley exige: «a) Una garantía complementaria de al menos un 5 por 100 del precio del contrato, que deberá prestarse en cualquiera de las formas contempladas en el artículo 108; b) El depósito de una cantidad en concepto de fianza, que se realizará de conformidad con lo establecido en el artículo 108.1, letra a), y que quedará constituida como cláusula penal para el caso de incumplimiento por parte del contratista». Debe advertirse que el precepto no determina realmente el importe de estas garantías. En el primer caso establece su cuantía mínima, mientras que en el segundo ni siquiera ello, lo que significa que deberá ser fijada, en atención a las circunstancias de cada supuesto, por la entidad contratante. El hecho, de otra parte, de que las indicadas cuenten, «en todo caso», con esa condición de «suficientes» hace pensar en la posibilidad de que puedan existir otras cuya aceptación sigue quedando en manos de la Administración.

En definitiva, la Administración puede, una vez declarado el concurso y con independencia de la fase en la que se encuentre, optar entre la continuidad del contrato -siempre que se aporten las garantías adicionales suficientes para su ejecución- o su ruptura. Una facultad que quizás deba excluirse, como viene manteniendo el Consejo de Estado en un criterio que no tiene por qué variar, en los supuestos en los que los pliegos del contrato, al amparo de la libertad de pactos que rige en la contratación administrativa, hayan previsto la resolución como consecuencia de la declaración de concurso o, en su caso -puede añadirse ahora-, de la apertura de la fase de liquidación ${ }^{17}$. De hecho, la norma que sirve al Consejo de Estado para apoyar su posición, el artículo 100.c) del TRCSP, que entre las «responsabilidades a que están afectas las garantías», sitúa «la incautación que pueda decretarse en los casos de resolución del contrato, de acuerdo con lo que en él o en esta Ley esté establecido» figura, sin variación alguna, en el artículo 110.d) del nuevo texto legal.

\section{Los efectos de la resolución}

Al igual que hemos hecho en el análisis de las causas de resolución y su aplicación, también aquí nos centramos en el examen de las novedades que aporta la LCSP, a las que añadiremos la exposición de aquellos extremos que hubieran merecido una atención que, sin embargo, el legislador no le ha dispensado. No nos adentramos, por tanto, en el examen de los efectos propios de la resolución por mutuo acuerdo que, como dispone en los mismos términos que disposiciones anteriores el artículo 213.1, «se acomodarán a lo válidamente estipulado por ellas». Tampoco merece la pena detenerse en el apartado siguiente del precepto que consagra la regla, tradicional igualmente en nuestro ordenamiento, que impone a la Administración, en caso de incumplimiento de «las obligaciones del contrato», el «pago de los daños y perjuicios que se irroguen al contratista». Entre las causas generales de resolución del contrato, a las que específicamente se refiere este precepto, solo existe una que tenga su origen en la infracción por la entidad contratante de las obligaciones que la vinculan, la demora en el pago que, transcurridos los plazos previstos en el artículo 198, faculta al contratista para romper el contrato con el derecho a ser indemnizado por los perjuicios que «como consecuencia de ello se originen», ámbito en el que, como la experiencia demuestra, surgen las mayores dificultades en la aplicación de una causa que, en sí misma, no suscita especiales problemas ${ }^{18}$.

\subsection{Las previsiones de carácter general.}

Dos previsiones de muy distinta naturaleza se dan cita aquí, las establecidas en los apartados $5 .^{\circ}$ y $6 .^{\circ}$ del precepto.

El primero el de ellos reproduce la regla, clásica en nuestras normas de contratación pública, que impone, «en todo caso», al acuerdo de resolución un «pronunciamiento expreso acerca de la procedencia o no de la pérdida, devolución o cancelación de la garantía que, en su caso, hubiese sido constituida». Ahora bien, aunque la interpretación literal del precepto pudiera llevar a pensar que el órgano competente cuenta

actividad profesional o empresarial», así como que la decisión correspondiera «al Juez concursal con la intervención de la Administración a través del correspondiente incidente concursal mediante informe vinculante de ésta».

La motivación de la enmienda señalaba que «referirse a «garantías suficientes» no es sino emplear un concepto jurídico indeterminado cuya concreción ha planteado no pocos problemas y las opiniones que sobre la materia se han vertido son ciertamente opuestas por lo que resulta razonable su concreción. Parece que la Administración no pueda rehusar una petición del contratante si son realmente suficientes; esto es, han de prestarse garantías adicionales a las originariamente prestadas por el contratista...».

17 En tal sentido, Dictamen 726/2016, de 22 de septiembre.

18 Sobre el alcance, en estos supuestos de resolución contractual, de los derechos económicos del contratista, puede verse, por ejemplo, la Sentencia del Tribunal Superior de Justicia de Madrid de 29 de diciembre de 2015 (JUR 2016/33939). 
con la capacidad para decidir discrecionalmente sobre el destino de la garantía, ello no es así. De una parte, porque el propio artículo 213 determina para ciertos supuestos de resolución contractual la solución procedente; de otra, porque su decisión habrá de respetar siempre la regla general que hoy recoge el artículo 111.1 que condiciona la devolución o cancelación de la garantía a que la resolución «se haya producido sin culpa del contratista».

El artículo 213.6 contiene una previsión aplicable a las resoluciones fundadas en diversas causas. Concretamente extiende a las derivadas de la situación de concurso del contratista y el incumplimiento por su parte de las obligaciones principal o esenciales del contrato, incluida la infracción del plazo de ejecución, una regla que el TRCSP solo establecía para aquéllas con origen en una modificación del contrato. La que, con el fin de asegurar la continuidad en la ejecución de la prestación, dispone que «al tiempo de incoarse el expediente administrativo de resolución» podrá iniciarse «el procedimiento para la adjudicación de un nuevo contrato» que «quedará condicionada a la terminación del expediente de resolución», aplicándose «la tramitación de urgencia» a «ambos procedimientos». Además, y hasta que se formalice el nuevo contrato, «el contratista quedará obligado, en la forma y con el alcance que determine el órgano de contratación, a adoptar las medidas necesarias por razones de seguridad, o indispensables para evitar un grave trastorno al servicio público o la ruina de lo construido o fabricado». Su retribución, a falta de acuerdo, se fijará por «el órgano de contratación, una vez concluidos los trabajos y tomando como referencia los precios que sirvieron de base para la celebración del contrato». El contratista «podrá impugnar esta decisión ante el órgano de contratación que deberá resolver lo que proceda en el plazo de quince días hábiles». Si el contratista no puede asegurar «las medidas indispensables establecidas en el párrafo anterior, la Administración podrá intervenir garantizando la realización de dichas medidas bien con sus propios medios, bien a través de un contrato con un tercero».

\subsection{Los efectos concretos de algunas causas de resolución}

El artículo 213 regula específicamente los efectos de la resolución del contrato por «incumplimiento culpable del contratista» y como consecuencia de su modificación.

\subsubsection{Las consecuencias de la resolución por incumplimiento culpable del contratista}

Los efectos de esta causa de resolución, ahora vinculada al incumplimiento por el contratista de «la obligación principal del contrato» o de «las restantes obligaciones esenciales» así calificadas en los pliegos en los términos establecidos en el artículo 211.1.f), han sido tradicionalmente controvertidos y han variado en todas las disposiciones sobre contratación pública que se han sucedido a lo largo de los siglos XIX y XX. La LCSP modifica, de nuevo, estos efectos para volver a la regla establecida en la Ley de 1995 poniendo fin así a la solución prevista en la de 2007 y que tantos problemas interpretativos había planteado al no prever expresamente en su artículo 208.4, 225.3 de su Texto Refundido, la incautación de la garantía como efecto necesario de una ruptura del contrato por este motivo, suscitando con ello la duda de si estaba reconociendo el derecho del contratista a su reintegro en la medida en que no fuera necesaria para indemnizar los daños y perjuicios causados a la Administración, pues la garantía, aquí la norma no generaba discusión, se encontraba adscrita a la compensación de tales daños, quedando además facultada la Administración para exigir al contratista la parte no cubierta, en su caso, por su importe ${ }^{19}$. Desde luego, el tenor literal de esos preceptos que, por primera vez en nuestra historia, no imponen la incautación automática de la garantía en estos supuestos, podía avalar esta interpretación que, sin embargo, encontraba un escollo importante en la disposición, artículo 102.1 del TRCSP, que condiciona su devolución a una resolución «sin culpa del contratista ${ }^{20}$. Los propios órganos consultivos darán buena cuenta de las dudas planteadas por el precepto que se va a derogar sin haberse alcanzado una interpretación uniforme, con el resultado de que una dis-

19 Disponía el precepto: «Cuando el contrato se resuelva por incumplimiento culpable del contratista, éste deberá indemnizar a la Administración los daños y perjuicios ocasionados. La indemnización se hará efectiva, en primer término, sobre la garantía que, en su caso, se hubiese constituido, sin perjuicio de la subsistencia de la responsabilidad del contratista en lo que se refiere al importe que exceda del de la garantía incautada».

20 En tal sentido, T. CANO CAMPOS "La incautación de la garantía definitiva en la resolución de los contratos por incumplimiento culpable del contratista", J. E. SORIANO GARCÍA (dir.), Por el Derecho y la Libertad. Libro Homenaje al Profesor Juan Alfonso Santamaría Pastor, lustel, Madrid, 2014, págs. 1.810-1.824. 
posición de carácter básico llamada, en consecuencia, a establecer una misma solución en el conjunto del territorio del Estado, terminaba aplicándose con contenidos muy diferentes en función de la interpretación que de ella se efectuara ${ }^{21}$. El propio Consejo de Estado en su dictamen al Anteproyecto de Ley dio cuenta de esta «problemática» y declaró el «pleno acierto» de la modificación legal en este punto.

El artículo 213.3 de la LCSP establece que «cuando el contrato se resuelva por incumplimiento culpable del contratista le será incautada la garantía y deberá, además, indemnizar a la Administración los daños y perjuicios ocasionados en lo que excedan del importe de la garantía incautada». Es, sin alteración alguna, la misma regla que, con precedentes claros en el Reglamento de Contratación de las Corporaciones Locales de $1953^{22}$, estuvo recogida en la Ley de 1995 y su Texto Refundido, lo que permite disponer para su interpretación de la doctrina de los órganos consultivos y la jurisprudencia recaída bajo la vigencia de estas disposiciones. Dos ideas merecen ser destacadas en el nuevo precepto. Así: a) La garantía se incauta por el simple hecho de la ruptura del contrato por culpa del contratista con independencia de que existan o no daños y perjuicios que indemnizar a la Administración y de cuál sea su importe ${ }^{23}$; y b) La garantía está afectada a la indemnización de esos daños y perjuicios y solo de no ser suficiente su cuantía, la Administración podrá ejercitar una acción de responsabilidad frente al contratista para resarcirse de los no cubiertos por ella. De esta forma, la garantía cumplirá con una función liquidatoria en los supuestos en los que los daños causados a la Administración por la extinción del contrato la superen y con una finalidad total o parcialmente punitiva en aquéllos otros en los que no ocasione daños o los provoque en una cifra inferior a la de su cuantía; lo que significa que esos daños habrán de quedar siempre debidamente demostrados y cuantificados ${ }^{24}$, pues solo así podrá saberse el montante de la indemnización a abonar por el contratista y sí la garantía incautada es suficiente a tal efecto ${ }^{25}$.

Los efectos establecidos en el artículo 213.3 se completan con la posible inhabilitación del contratista establecida en el artículo 71.2.d) de la LCSP que prohíbe contratar «con las entidades comprendidas en el artículo 3 de la presente Ley» a quienes hubieran «dado lugar, por causa de la que hubieran sido declarados culpables,

21 Toda vez que el propio Consejo de Estado y otros órganos consultivos mantendrán, en una interpretación avalada por algunos pronunciamientos judiciales, la posible devolución de la garantía al contratista que, sin embargo, otras instancias consultivas autonómicas denegarán. Al respecto puede verse C. BARRERO RODRÍGUEZ, "Los efectos de la resolución de los contratos administrativos: resolución por concurso y por incumplimiento del contratista. La conveniencia de una reforma" (Revista de Administración Pública, núm. 196, 2015, págs. 82-94).

22 Su artículo 97 estipulaba que la resolución del contrato por incumplimiento del contratista determinaba la «pérdida de la garantía provisional o definitiva», a lo que el precepto siguiente añadía que si «resultare insuficiente para hacer efectivas las responsabilidades del licitador o contratista, se procederá contra los demás bienes del deudor».

23 Cabe notar que las normas de contratación pública no han determinado nunca, tampoco lo hace la Ley de 2017, cuando existe culpa del contratista en el incumplimiento. Han sido los órganos consultivos y la jurisprudencia los que han establecido que esta circunstancia concurre cuando el contratista actúa sin la diligencia que le es exigible, de ahí que quede exonerado de responsabilidad en los supuestos en los que su incumplimiento trae causa de un hecho «imprevisible o inevitable» o de una previa infracción del contrato por la Administración que le impide atender a sus obligaciones (Un desarrollo del tema puede encontrarse en C. BARRERO RODRÍGUEZ, La resolución de los contratos administrativos por incumplimiento del contratista, op. cit., págs. 68-129).

24 Es importante insistir en esta idea, toda vez que, bajo la vigencia de la Ley de 1995 y de su Texto Refundido, ciertos autores y algunos dictámenes de diferentes órganos consultivos siguieron manteniendo esa doctrina, desarrollada en aplicación de disposiciones más antiguas, de acuerdo con la cual la garantía sería una cláusula que tasa esos perjuicios de difícil cuantificación que comporta siempre la ruptura del contrato sin la realización de su objeto. Una tesis que, como estudié en una ocasión anterior, quizás no tuviera cabida, como tampoco la tendría hoy, en el régimen establecido por la disposición de ese año, cuya correcta aplicación exigía la acreditación y cuantificación de los daños causados a la Administración (La resolución de los contratos administrativos por incumplimiento del contratista, Lex Nova, Valladolid 2006, págs. 189-193). Hay que reconocer, no obstante, que el Consejo de Estado en su dictamen al Anteproyecto de Ley no parece apuntar en esta línea al manifestar que «el incumplimiento culpable determinará para el contratista la pérdida de la fianza, que desarrollará por sí misma una función punitiva, desincentivando la inobservancia de lo pactado, y permitirá a la Administración verse resarcida de los daños y perjuicios que dicho incumplimiento ocasiona, sin necesidad de demostrar su cuantificación, como ahora sucede. Solamente si se estima que tales daños y perjuicios sobrepasan el importe de la garantía definitiva incautada, la Administración tendrá que afrontar la justificación de su importe, para poder ejercer su prerrogativa de depurar la responsabilidad contractual del adjudicatario, con la consiguiente exigencia de la suma excedentaria».

${ }^{25}$ La acreditación y valoración de los daños se ha de producir, como establece el artículo 113 del RGCAP, «por el órgano de contratación en decisión motivada previa audiencia del mismo», lo que puede tener lugar, como siempre han reconocido el Consejo de Estado y otros órganos consultivos en un criterio que no tiene por qué variar, tanto en el propio acuerdo de resolución del contrato como en el curso de un procedimiento posterior (Dictámenes, por ejemplo, del Consejo de Estado 112/2016, de 31 de marzo, 612/2016, de 20 de julio, 716/2016, de 6 octubre o 750/2016, de 10 de noviembre; o en los Dictámenes, entre otros, 43/2017, de 27 de febrero, del Consejo consultivo de Aragón o 46/2017, de 24 de febrero del Consejo jurídico de la Región de Murcia), pues lo importante es que el contratista pueda rebatir la valoración efectuada por la Administración. Cuestión distinta es que no se muestre interesado en discutirla en las hipótesis en las que la propia Administración los considera reparados con la garantía, toda vez que ésta, en ningún caso, va a reintegrársele. 
a la resolución firme de cualquier contrato celebrado» con una entidad, igualmente, «de las comprendidas en el artículo 3 de la presente Ley». Una prohibición que el apartado $3 .^{\circ}$ del precepto extiende «a aquellas empresas de las que, por razón de las personas que la rigen o de otras circunstancias pudiera presumirse que son continuación o que derivan, por transformación, fusión o sucesión, de otras empresas en las que hubiesen concurrido aquellas». La prohibición de contratar, artículo 72.5 , se ha de declarar «siguiendo el procedimiento que en las normas de desarrollo de esta Ley se establezca» y que, como dispone el apartado 7.c) del precepto, «no podrá iniciarse si hubiesen transcurrido más de tres años» computados «desde la fecha en la que fuese firme la resolución del contrato». La prohibición no podrá exceder, artículo 72.6, de tres años frente a los cinco que regían bajo la vigencia del TRCSP, a contar, artículo 73.3, «desde la fecha de inscripción en el registro correspondiente» ${ }^{26}$, extendiendo sus efectos, artículo 72.1 , a todas «las entidades comprendidas en el artículo 3 de la presente Ley»; esto es, a todas las incluidas en su ámbito de aplicación, lo que supone igualmente un cambio de criterio respecto de la norma precedente, en cuya aplicación, artículo 61.3 del TRCSP, solo alcanzaba «a la contratación con la Administración o entidad del sector público competente para su declaración», sin perjuicio de la posibilidad reconocida al Ministerio correspondiente para extender sus efectos.

Finalmente cabe llamar la atención sobre el silencio de la LSCP en relación con los supuestos en los que al incumplimiento del contratista causante de la resolución del contrato se suma el de la entidad contratante. Unas hipótesis frecuentes en la doctrina de los órganos consultivos y en la jurisprudencia contenciosoadministrativa, cuya regulación, al igual que lo hiciera en su Dictamen 1270/1993, de 2 de diciembre, al Anteproyecto de la Ley de Contratos de 1995, reclamó sin éxito el Consejo de Estado durante la tramitación de la disposición de $2017^{27}$. Cabe, desde luego, manifestar la frecuencia con la que se presentan supuestos de esta naturaleza y la disparidad de respuestas que ante ellos ofrecen los distintos órganos consultivos y la jurisprudencia, lo que hacía, sin duda, conveniente una regulación cuya ausencia no cabe sino lamentar. Tampoco atiende, de otra parte, la nueva LCSP, en el sentido apuntado igualmente por esa misma doctrina y jurisprudencia, a la posible modulación de las consecuencias de la resolución en atención al distinto alcance del incumplimiento del contratista y las concretas circunstancias en las que se ha producido.

\subsubsection{Los efectos de una resolución ligada a la modificación del contrato}

El artículo 213.4 de la LCSP regula las consecuencias propias de la resolución del contrato con origen en su modificación, supuestos en los que reconoce el derecho del contratista «a una indemnización del 3 por ciento del importe de la prestación dejada de realizar», aplicable tanto a los supuestos en los que la resolución se impone ante la imposibilidad de ejecutar la prestación sin una variación del contrato que su regulación no permite, como a aquéllos otros en los que opera con carácter potestativo al exceder la cuantía de la modificación acordada del límite legalmente previsto. En ambos casos, sin embargo, el propio artículo 213.4 reconoce la posible exclusión de este derecho. En el primero de ellos, cuando «la causa sea imputable al contratista», esto es, cuando él sea el responsable de la situación que determina que sea necesaria esa modificación que no puede efectuarse, circunstancia que deberá determinarse a partir de una valoración de cada uno de los casos en los que pueda presentarse. En el segundo, cuando «rechace la modificación contractual propuesta por la Administración al amparo del artículo 205». Esta previsión, que no figuraba en las versiones iniciales del Anteproyecto de Ley, se incorpora tras las consideraciones efectuadas por el Consejo de Estado en su dictamen al Anteproyecto ${ }^{28}$, deja sin indemnización al contratista en los casos en los que ejercita la facultad resolutoria del contrato, circunscribiendo así el ámbito de aplicación de la previsión a las hipótesis en las que es la Administración la que, en aplicación del artículo 212.2, insta la resolución del contrato.

26 El apartado anterior de este mismo precepto exige que la prohibición de contratar, «una vez adoptada la resolución correspondiente», se comunique «sin dilación para su inscripción al Registro Oficial de Licitadores y Empresas Clasificadas del Sector Público o el equivalente en el ámbito de las Comunidades Autónomas, en función del ámbito de la prohibición de contratar y del órgano que la haya declarado».

27 Así lo hizo en su dictamen al Anteproyecto de Ley en el que propuso, incluso, cual podría ser el texto de la disposición que las regulase: «Excepcionalmente, la incautación de la garantía podrá ser modulada en el caso de que al incumplimiento culpable del contratista hubiera concurrido la actuación de la Administración».

${ }_{28}$ Advertía el Consejo que «no debe surgir el derecho del contratista» cuando, «planteada la modificación por la Administración y estando la misma amparada por el artículo 205, el contratista decline firmar el proyecto modificado». Y ello, razonaba, «por cuanto una cosa es dotar de carácter potestativo a la reforma contractual por encima del $20 \%$ del precio inicial y otra distinta incentivar al contratista para que la rechace abonándole una indemnización en tal coyuntura. Podrá o no prestar su conformidad a la modificación, pero no es procedente resarcir al contratista con el 3\% de la prestación dejada de realizar en el supuesto en el que se niegue a aceptarla». 
Nada dispone específicamente la LCSP sobre el destino de la garantía en estos supuestos. Tampoco lo hacía el Texto Refundido de 2011 ante lo que los órganos consultivos no dudaron en declarar la procedencia de su devolución si, como con carácter general ocurre en estos casos, nos encontramos ante «una causa de resolución ajena al incumplimiento de la empresa contratista» ${ }^{29}$. Un criterio que no tiene por qué variar ante la coincidencia, en este punto, de la regulación actual con la de la norma precedente.

\subsection{La insuficiencia del artículo 213 de la LCSP en relación con algunas causas de resolución}

\subsubsection{Consideraciones generales}

El análisis de este precepto no debe concluir sin la exposición de las carencias que presenta respecto de algunas de las causas de resolución legalmente previstas, concretamente de la derivada de la declaración de concurso del contratista y del impago "de los salarios a los trabajadores que participan en la ejecución del contrato y el incumplimiento de las condiciones establecidas en los convenios colectivos». Ya hemos destacado, de otra parte, las insuficiencias de su regulación en el extremo relativo a los supuestos de concurrencia de Administración y contratista en el incumplimiento del contrato, debiendo añadirse ahora que el artículo 213 tampoco se pronuncia sobre los efectos propios de una resolución basada en la infracción del plazo contractual, de la que tan solo determina en su apartado $3 . .^{\circ}$, reiterando la regla ya establecida en el artículo 193.4, que cada vez que las penalidades por demora «alcanzasen un múltiplo del 5 por ciento del precio del contrato», el «órgano de contratación estará facultado para proceder a la resolución del mismo o acordar la continuidad de su ejecución con imposición de nuevas penalidades». No obstante, las consecuencias de la resolución por este motivo no han suscitado nunca discusión al constituir un incumplimiento por el contratista de sus obligaciones esenciales al que, por consiguiente, resultan aplicables los efectos que hoy prevé el párrafo $3 .^{\circ}$ del precepto.

\subsubsection{La resolución por concurso}

Una de las principales lagunas del artículo 213 es la que afecta a los casos de resolución del contrato con origen en la situación de concurso del contratista, de la que nada determina el precepto al haber desaparecido la norma del artículo 225.4 del TRCSP anterior que establecía que «sólo se acordará la pérdida de la garantía en caso de resolución del contrato por concurso del contratista cuando el concurso hubiera sido calificado como culpable ${ }^{30}$, Ese precepto, sin embargo, no se pronunciaba sobre la posible exigencia al contratista de una indemnización por los daños y perjuicios que la ruptura anticipada del contrato hubiera podido ocasionar a la Administración, reconocida, sin embargo, por la jurisprudencia y los órganos consultivos, en las hipótesis en las que el concurso fuera culpable con fundamento en las consecuencias propias de la resolución "por incumplimiento culpable del contratista», al estimarse que ésta es la situación que, en definitiva, se produce en estos supuesto ${ }^{31}$; parecer que también compartían numerosos autores ${ }^{32}$. Más problemáticos resultaban los casos de concursos fortuitos respecto de los que no se encuentran pronunciamientos en esa jurisprudencia y doctrina que avalen de manera clara ese posible deber del contratista indemnizar los daños que hubiera podido causar a la Administración, posibilidad que, en algunos supuestos, parece, incluso, excluirse ${ }^{33}$.

En definitiva, los efectos de la resolución por este motivo parecían necesitados de una regulación que abordara éstos y otros extremos que en su ámbito se presentan ${ }^{34}$. Una necesidad a la que, sin embargo,

29 En términos tomados, por ejemplo, del Dictamen 195/2015, 9 de abril del Consejo de Estado.

30 La previsión tenía su origen en la modificación del artículo 208.4 de la LCSP por el RDL 6/2010, de 9 de abril efectuada con el objeto, según manifiesta expresamente su Preámbulo, de «favorecer la actividad empresarial».

31 En tal sentido, Sentencia del Tribunal Superior de Justicia de Cataluña de 20 de septiembre de 2001 (JUR 2011/17911) y Dictámenes, entre otros, 136/2008 de la Comisión Jurídica asesora de Euskadi; 96/2009, de 13 de mayo, del Consejo consultivo de CastillaLa Mancha; 471/2012, de 26 de julio, del Consejo consultivo de Madrid; o 273/2013, de 22 de julio, del Consejo consultivo de Canarias.

32 Así, M. CARLON, M. (Comentario al artículo 67), en ROJO, A. y E. BELTRÁN, Comentarios de la Ley Concursal, ThomsonCivitas, Madrid, 2004, págs. 1.246-1.247), M. I. LINARES GIL ("Concurso de acreedores y contratación administrativa”, Revista de Derecho Concursal y Paraconcursal, núm 14, 2011, pág. 203) o T. VÁZQUEZ LEPINETTE ("Los efectos del concurso sobre los contratos administrativos a la luz del Real Decreto-Ley 6/2010", Anuario de Derecho concursal, núm. 22, 2011, pág. 330).

33 Así en el Dictamen 113/2016, de 16 de febrero, del Consejo de Estado.

34 De entre los que destaca, sin duda, la concurrencia de esta causa de resolución con la basada en el incumplimiento por el contratista de sus obligaciones y que no siempre se resuelven de manera satisfactoria con la regla que aboga por la aplicación preferente 
no ha sido sensible la LCSP que no solo no ha regulado las posibles consecuencias indemnizatorias que pudieran derivar en favor de la entidad contratante en estos supuestos de ruptura del vínculo contractual, sino que además ha venido a plantear un nuevo problema inexistente bajo el régimen jurídico anterior, el del destino de la garantía, pues ha eliminado, lo que el Consejo de Estado en su dictamen al Anteproyecto de Ley consideró que debía «reevaluarse», la previsión del artículo 225.4 del TRCSP que vinculaba su pérdida a la calificación del concurso. En ausencia de reglas específicas, habrá que estar a lo que, en cumplimiento del artículo 213.5, pueda disponer la Administración en el acuerdo de resolución que deberá tener en cuenta lo dispuesto en el artículo 111.1 que condiciona la devolución de la garantía al hecho de que la resolución se haya producido «sin culpa del contratista». De esta forma, podría mantenerse, lo que supondría la pervivencia de la solución del TRCSP, su incautación en los supuestos de concurso culpable, de aceptarse, lo que no está nada claro, que el hecho de que el concurso cuente con esta calificación supone que también es culpable la resolución del contrato que trae causa de esa declaración ${ }^{35}$. Confiemos en que los órganos consultivos y los tribunales aclaren pronto esta importante cuestión. De igual modo, habrá que permanecer atentos a ver si siguen mostrándose favorables a una posible indemnización a la Administración por los daños causados cuando el concurso cuente con esa calificación. También es de esperar, finalmente, que aclaren las consecuencias de la resolución en las hipótesis, por el contrario, de concursos fortuitos.

La LCSP sí establece en su artículo 71.1.c) la prohibición de contratar de las personas que hayan «solicitado declaración de concurso voluntario», hayan «sido declaradas insolventes en cualquier procedimiento», «declaradas en concurso, salvo que en este haya adquirido eficacia un convenio o se haya iniciado un expediente de acuerdo extrajudicial de pagos» o «inhabilitadas» conforme a la LC «sin que haya concluido el periodo de inhabilitación fijado en la sentencia de calificación del concurso ${ }^{36}$. Igualmente prevé la posible cesión del contrato aún abierta la fase de liquidación y sin necesidad de que concurra la exigencia general establecida en el artículo 214.2.b) de que el contrato se encuentre ejecutado en «al menos un 20 por 100» de su importe del contrato o, cuando se trate de un contrato de concesión de obras o de servicios, haya sido explotado «durante al menos una quinta parte del plazo de duración».

\subsubsection{La ruptura del contrato por la causa prevista en el artículo 211.1.i)}

Tampoco regula la LCSP las consecuencias propias de una resolución por la nueva causa establecida en el artículo 211.1.i), el incumplimiento por el contratista de sus obligaciones con los trabajadores, lo que deja completamente indefinidos estos efectos ante las dificultades existentes para buscar una solución en la aplicación supletoria de las reglas previstas en el artículo 213 para otros supuestos de resolución contractual. En principio, pudiera pensarse en la inserción de estos casos en el ámbito de aplicación de su apartado $3 .^{\circ}$, bajo la premisa de que nos encontramos ante hipótesis de incumplimiento por el contratista de sus obligaciones esenciales. Ahora bien, siendo ello cierto, no pueden ocultarse las sustanciales diferencias existentes entre la causa de resolución regulada en el artículo 211.1.i) y la establecida en la letra f) para la que están previstos los efectos determinados en el artículo 213.3. Y es que ésta última sanciona los incumplimientos surgidos en el ámbito de la relación contractual, mientras que la letra i) se proyecta, sin embargo, sobre incumplimientos producidos en una relación jurídica ajena a la Administración titular del contrato. El deber de indemnizar a la entidad contratante los daños causados por la resolución, principal efecto previsto

de la causa de resolución primera en el tiempo. En los Dictámenes, entre otros, 181/2016, de 31 de marzo y 182/2016, de 14 de abril, del Consejo de Estado; 99/2014, de 9 de abril del Consejo jurídico de la Región de Murcia; 459/2014, de 4 de septiembre, del Consejo jurídico consultivo de Valencia; 449/2015, de 22 de octubre, del Consejo consultivo de Extremadura; y 15/2016, de 21 de enero, del Consejo consultivo del Principado de Asturias o en las Sentencias del Tribunal Superior de Justicia de Madrid de 16 de octubre de 2015 (JUR 2015/271911) o de La Rioja de 3 de marzo de 2016 (JUR 2016/77958) pueden encontrarse diversos ejemplos de estos supuestos extraordinariamente frecuentes en la práctica.

35 El Dictamen, entre otros, 20/2016, de 27 de junio, del Consejo consultivo de la Rioja advierte que «una cosa es que el contratista pueda ser declarado culpable de un incumplimiento contractual y otra que sea culpable del concurso de acreedores, ya que la situación de insolvencia del concursado puede deberse a otras causas». En la misma línea puede verse la Sentencia del Juzgado de lo Contencioso-administrativo núm. 12 de Barcelona de 23 de enero de 2017 (JUR 2017/138574).

36 Sobre la inhabilitación del contratista en estos supuestos pueden verse, entre otras, las consideraciones de I. DEL GUAYO CASTIELLA (Contratos del sector público y concurso de acreedores, op. cit., págs. 31-61), M. LINARES GIL "Concurso de acreedores y contratación administrativa tras el RDL 6/2010" (op. cit., págs. 196-7), T. VÁZQUEZ LEPINETTE ("Los efectos del concurso sobre los contratos administrativos a la luz del Real Decreto-Ley 6/2010”, op. cit., págs. 317-321) o I. FERNÁNDEZ TORRES (“Algunas consideraciones en torno a los efectos del concurso sobre los contratos del sector público: una perspectiva ius privatista", Revista Española de Derecho Administrativo, núm. 143/2009, págs. 500-506). 
en este precepto, cobra sentido en los casos en los que es la Administración, en cuanto parte de la relación de jurídica, la que padece las consecuencias negativas de los incumplimientos del contratista, lo que no sucede en los supuestos en los que se sanciona, no la infracción del propio contrato, sino deberes impuestos al margen de la relación contractual por un orden completamente diferente como es el laboral. En suma, los presupuestos de hecho de las causas de resolución de las letras f) e i) del artículo 211.1 de la LCSP son muy diferentes, de ahí la imposibilidad, en principio, de aplicar las consecuencias previstas en el artículo 213.3 para la primera ellas a las establecidas en la letra i), por más que, en ambos casos, exista un incumplimiento del contratista. De otra parte, tampoco debe de pasar por alto que la aplicación del artículo 213.3 exige como condición sine qua non que el incumplimiento del contratista sea culpable, circunstancia que, en presencia de la causa prevista en el artículo 211.1.i), habrá que determinar no se sabe por quién ni de acuerdo con qué parámetros y que puede ser, incluso, que no concurra.

La única consecuencia posible, a partir de lo dispuesto en el artículo 213 , de una resolución fundada en este motivo es la de la eventual pérdida de la garantía adoptada por el órgano competente en el acuerdo de resolución de conformidad con lo dispuesto en su apartado $5 .^{\circ}$, lo que exige igualmente la culpa del contratista, dado que, en caso, contrario, este efecto no será posible de acuerdo con el artículo 111.1 de la Ley.

Habrá que esperar a la interpretación que puedan ofrecernos las distintas instancias consultivas y la jurisprudencia. El tiempo determinará también el grado de aplicación que esta causa de ruptura del contrato pueda tener.

\section{LAS CAUSAS DE RESOLUCIÓN PROPIAS DE CADA CONTRATO}

Abordamos seguidamente, de forma más breve, las modificaciones de la LCSP relativas a la resolución de los diferentes contratos que regula. Aquí sus innovaciones, más reducidas en número y en muchos casos incorporadas durante la tramitación parlamentaria de la Ley, son, salvo alguna excepción, de menor trascendencia que las que afectan al régimen general de resolución del contrato.

\section{El contrato de obras}

La regulación de la resolución del contrato de obras en los artículos 245 y 246 de la LCSP coincide sustancialmente con la establecida en el TRCSP, procedente, a su vez, de disposiciones más antiguas.

Así, y en lo que hace en primer término, a las causas propias de resolución de este contrato, el artículo 245 mantiene las ya previstas en el 237 de la disposición anterior: a) La demora en la comprobación del replanteo; b) La suspensión de la iniciación de las obras; c) La suspensión de las obras en curso de ejecución; y d) El desistimiento. No obstante, presenta algunas modificaciones de interés. En la letra a) se introduce la exigencia de que la demora en la comprobación del replanteo sea, a los efectos de poder fundar la resolución del contrato, «injustificada». Ahora bien, no puede considerarse que aquí exista realmente una novedad, toda vez que esta exigencia viene a sustituir a la remisión que la disposición de 2011 efectuaba, y que ahora desaparece, al precepto relativo a la comprobación del replanteo, el artículo 229, que, al igual que el 237 de la nueva Ley, establecía la posibilidad de que ésta pudiera efectuarse fuera del plazo dispuesto al efecto «en casos excepcionales justificados», considerándose cualquier otro incumplimiento causa de resolución. En principio, pues, cabe identificar esos supuestos de «demora injustificada» a los que alude el nuevo artículo 245.a) con aquellos que no encuentran cobertura en esos "casos justificados excepcionales» a los que se refiere el 237. La segunda novedad del artículo 245 de la LCSP es la relativa al plazo de suspensión del inicio de las obras a los efectos de que el contratista pueda ejercitar su facultad resolutoria del contrato, que pasa de los seis meses existentes en la disposición anterior a las cuatro que establece la letra b) del nuevo precepto $^{37}$.

Tampoco se aprecian variaciones sustanciales en la regulación que ofrece el artículo 246 de la LCSP de los efectos de la resolución del contrato. Se sigue reconociendo, en idénticos términos a los de la disposición

37 En relación con esta causa ha de notarse también que en la Ley de 2017 ha desaparecido el precepto, el artículo 238 , del Texto Refundido de 2011, sobre «suspensión de la iniciación de la obra», lo que ha de considerarse lógico en la medida en que no aportaba nada a lo que ya disponían los artículos 237 y 239 . El precepto establecía que «en la suspensión de la iniciación de las obras por parte de la Administración, cuando ésta dejare transcurrir seis meses a contar de la misma sin dictar acuerdo sobre dicha situación y notificarlo al contratista, éste tendrá derecho a la resolución del contrato». 
anterior, que «dará lugar a la comprobación, medición y liquidación de las obras realizadas con arreglo al proyecto, fijando los saldos pertinentes a favor o en contra del contratista», que tendrá que ser citado "en el domicilio que figure en el expediente de contratación, para su asistencia al acto de comprobación y medición»; y se mantienen, en cifras objetivas, las indemnizaciones a las que tendrá derecho ante los diferentes supuestos de ruptura del contrato determinados en el precepto anterior, con la novedad de que se aclara que en su cálculo, referido siempre al precio de adjudicación, ha de excluirse el IVA. Así, en los casos de resolución por demora injustificada en la comprobación del replanteo, la indemnización será «equivalente al 2 por 100 del precio de la adjudicación»; en los de desistimiento o suspensión antes de la iniciación de las obras por plazo superior a cuatro meses, «el 3 por 100 del precio de adjudicación»; y en los de desistimiento o suspensión de obras ya iniciadas por plazo superior a ocho meses, el «6 por cien del precio de adjudicación del contrato de las obras dejadas de realizar en concepto de beneficio industrial, IVA excluido, entendiéndose por obras dejadas de realizar las que resulten de la diferencia entre las reflejadas en el contrato primitivo y sus modificaciones aprobadas y las que hasta la fecha de notificación del desistimiento o la suspensión se hubieran ejecutado» ${ }^{38}$. La Ley mantiene finalmente en el apartado $5 .^{\circ}$ del precepto, previsión tomada de la norma anterior sin variación alguna, que «cuando las obras hayan de ser continuadas por otro empresario o por la propia Administración, con carácter de urgencia, por motivos de seguridad o para evitar la ruina de lo construido, el órgano de contratación, una vez que haya notificado al contratista la liquidación de las ejecutadas, podrá acordar su continuación, sin perjuicio de que el contratista pueda impugnar la valoración efectuada ante el propio órgano. El órgano de contratación resolverá lo que proceda en el plazo de quince días».

\section{El contrato de concesión de obra pública}

La LCSP determina las causas de resolución del contrato de concesión de obra pública en su artículo 279 que certeramente suprime de su listado, sí figuraban en el artículo 269 del TRCSP, las causas generales de resolución del contrato, que quedan sustituidas por una remisión al artículo 211 «con la excepción de las contempladas en sus letras d) y e)»; esto es, la demora en el cumplimiento de los plazos por parte del contratista y de la Administración en el pago. Como causas específicas de resolución de este contrato, las letras a), b), d) y e) del precepto recogen, en términos idénticos o sustancialmente coincidentes con los de la disposición precedente, las siguientes causas de resolución, «La ejecución hipotecaria declarada desierta o la imposibilidad de iniciar el procedimiento de ejecución hipotecaria por falta de interesados autorizados para ello en los casos en que así procediera, de acuerdo con lo establecido en la Ley»; "La demora superior a seis meses por parte del órgano de contratación en la entrega al concesionario de la contraprestación, de los terrenos o de los medios auxiliares a que se obligó según el contrato» ${ }^{39}$; "La supresión de la explotación de las obras por razones de interés público» ${ }^{40}$ y «La imposibilidad de la explotación de la obra pública como consecuencia de acuerdos adoptados por la Administración concedente con posterioridad al contrato». La LCSP introduce, sin embargo, en su artículo 279.c) modificaciones de interés en la causa que en la letra g) del 269 del TRCSP figuraba como «el rescate de la explotación de la obra pública por el órgano de contratación», entendiéndose por tal «la declaración unilateral» de ese órgano, "discrecionalmente adoptada», por la que "dé por terminada la concesión, no obstante la buena gestión de su titular". De una parte, el nuevo precepto sustituye la decisión «discrecionalmente adoptada» por «la adoptada por razones interés público», exigencia, no obstante, que puede considerarse implícita en la figura. De otra, impone que el rescate de la explotación de la obra, condición inexistente en esa norma, se produzca para «su gestión directa por la Administración», siendo necesaria además, lo que no parece fácil, «la acreditación de que dicha gestión directa es más eficaz y eficiente que la concesional» ${ }^{41-42}$.

38 En la Sentencia del Tribunal Superior de Justicia de Madrid de 6 de abril de 2016 (JUR 2016/116569) puede encontrarse un análisis de los derechos de contratista en los casos de resolución por desistimiento de la Administración de las obras.

39 Sobre la resolución basada en este motivo puede verse la STS de 22 de diciembre de 2016 (RJ 2016/6327).

40 Causa de resolución que analiza, por ejemplo, la Sentencia de 23 de mayo de 2016 del Tribunal Superior de Justicia de Castilla y León, Sala de Valladolid (JUR 2016/204850.

41 La previsión tiene su origen en la enmienda número 930 presentada en el Congreso de los Diputados por el Grupo mixto que proponía también, lo que sin embargo no fue aceptado, la incorporación del siguiente texto: «y que no resulta posible introducir competencia efectiva. A este último efecto deberá solicitarse informe de la autoridad de competencia. Los requisitos del rescate serán de aplicación a la expropiación de la concesión o de la empresa concesionaria».

42 Sobre el rescate en el nuevo marco comunitario de la contratación pueden verse las reflexiones de J. M. GIMENO FELIU, J. M., P. SALA SÁNCHEZ, P. y G. QUINTERO OLIVARES, G., El interés público y su satisfacción con la colaboración pública-privada. 
El artículo 279.f) mantiene, finalmente, el secuestro como causa de resolución de este contrato, al que añade la intervención fijando su plazo posible por remisión al artículo 263.3.

El artículo 280 regula los «efectos de la resolución» con algunas innovaciones respecto de la regulación precedente. La Ley establece un régimen que varía, al igual que en el artículo 271 del TRCSP, en función de cual haya sido la parte a la que es imputable el incumplimiento. De esta forma, el apartado $1 .^{\circ}$ establece que «en los supuestos de resolución por causa imputable a la Administración, esta abonará en todo caso al concesionario el importe de las inversiones realizadas por razón de la expropiación de terrenos, ejecución de obras de construcción y adquisición de bienes que sean necesarios para la explotación de la obra objeto de la concesión, atendiendo a su grado de amortización. Al efecto, se aplicará un criterio de amortización lineal. La cantidad resultante se fijará dentro del plazo de tres meses, salvo que se estableciera otro en el pliego de cláusulas administrativas particulares». No hay aquí más novedades que la reducción a la mitad, tres meses frente a los seis anteriormente previstos, del plazo existente para la fijación de la cantidad a abonar al contratista ${ }^{43}$. En los casos, añade este mismo artículo 280.1, «en que la resolución se produzca por causas no imputables a la Administración, el importe a abonar al concesionario por cualquiera de las causas posibles será el que resulte de la valoración de la concesión, determinado conforme a lo dispuesto en el artículo $281 »$. La LCSP sustituye aquí la enumeración de los conceptos de la disposición anterior que determinaban el importe a abonar: «la expropiación de terrenos, ejecución de obras y adquisición de bienes que deban revertir a la Administración» por una fórmula comprensiva de éstos y otros posibles, «por cualquiera de las causas posibles» ${ }^{44}$. El precepto, en este primer apartado, concluye con la determinación, lo que sin duda otorga seguridad jurídica, de cuando «la resolución de la concesión no es imputable a la Administración», cuando «obedezca a alguna de las causas previstas en las letras a), b), y f) del artículo 211, así como en las letras a) y f) del artículo $279{ }^{4}{ }^{4}$.

El artículo 280.2, de otra parte, reitera la regla general ya establecida en el artículo 213.3 al disponer, para el caso de que «el contrato se resuelva por causa imputable al concesionario», la incautación de la garantía y el deber, además, de «indemnizar a la Administración los daños y perjuicios ocasionados en lo que exceda del importe de la garantía incautada ${ }^{46}$. El apartado $3 .^{\circ}$ se ocupa, por el contrario, de los supuestos en los que la resolución tenga su origen en la actuación de la entidad contratante, los de «las letras b), c), d) y e) del artículo 279, y en general en los casos en que la resolución del contrato se produjera por causas imputables a la Administración y sin perjuicio de lo dispuesto en el apartado 1 de este artículo». En todos ellos, «la Administración concedente indemnizará al concesionario por los daños y perjuicios que se le irroguen», estableciendo el propio precepto las reglas conforme a las cuales se ha de determinar esta indemnización.

Otras disposiciones completan la regulación de este precepto en términos coincidentes con los del TRCSP. Así, el apartado $4 .^{\circ}$ prevé la posibilidad de que el órgano de contratación acuerde también la resolución de los contratos para el aprovechamiento de zonas complementarias o de explotación comercial; el $5 .^{\circ}$ el incumplimiento por el concesionario de «las obligaciones del beneficiario en las expropiaciones»; y el $6 .^{\circ}$ el derecho del contratista al "abono del interés de demora» en los supuestos de resolución ante el retraso superior a seis meses por el órgano de contratación «en la entrega al concesionario de la contraprestación, de los terrenos o de los medios auxiliares a que se obligó según el contrato». Los artículos 281 y 282 de la LCSP recogen, también sin variación alguna en sus términos, las disposiciones de los artículos 271 bis) y 271 ter) del TRCSP incorporados por la Ley 40/2015, de Régimen Jurídico del Sector Público, sobre el

Fundamentos, equilibrios y seguridad jurídica, Cámara de Comercio de Barcelona, Barcelona, 2017, págs. 69-72.

43 Modificación introducida en el Proyecto de Ley por el Congreso de los Diputados en donde se acepta la enmienda propuesta por «Ciudadanos» (enmienda número 403) con la siguiente justificación: «El éxito de la concesión de obras, como instrumento de colaboración público-privado, depende fundamentalmente de la posibilidad de financiar las obras objeto de concesión. Es necesario por tanto extremar la seguridad jurídica y reducir en lo posible la incertidumbre respecto de los derechos económicos de las partes implicadas en el supuesto de resolución anticipada del contrato».

44 Una previsión que tiene su origen en la enmienda número 404 presentada por el Grupo parlamentario Ciudadanos en el Congreso de los Diputados.

45 Esto es, a la muerte o incapacidad sobrevenida del contratista individual o la extinción de la personalidad jurídica de la sociedad contratista, la declaración de concurso o de insolvencia en cualquier otro procedimiento, el incumplimiento por el contratista de sus obligaciones, la ejecución hipotecaria declarada desierta o la imposibilidad de iniciar el procedimiento de ejecución hipotecaria por falta de interesados autorizados para ello en los casos en que así procediera y el secuestro o intervención de la concesión.

46 Esta es hoy, en efecto, la regla general por lo que el contrato de concesión de obra pública no muestra en este punto ninguna singularidad en relación con el resto de los tipos contractuales. No fue así, sin embargo, durante la vigencia de la Ley de 2007 y de su Texto Refundido, en donde tales efectos no coincidían con los entonces dispuestos en los artículos 208.4 y 225.3 , respectivamente. 
«nuevo proceso de adjudicación en concesión de obras en los casos en los que la resolución obedezca a causas no imputables a la Administración» y la «determinación del tipo de licitación de la concesión de obras en los casos en los que la resolución obedezca a causas no imputables a la Administración». El artículo 283 finalmente regula el «destino de las obras a la extinción de la concesión» aquí, sí, con dos novedades de interés respecto de la regulación precedente. La que exige cuando se proceda, al término de la concesión, a la entrega a la Administración de los «los bienes e instalaciones» que corresponda, que se levante «un acta de recepción formal», cuyo contenido se ajustará a los establecido en el artículo 243; y la que en el apartado $3 .^{\circ}$ dispone que «los bienes afectos a la concesión que vayan a revertir a la Administración no podrán ser objeto de embargo».

Por último, y aunque al margen de los preceptos que comentamos, cabe destacar que los acuerdos de rescate de las concesiones tanto de obras como de servicios cuyo valor supere los tres millones de euros son susceptibles del recurso especial en materia de contratación de acuerdo con la nueva regulación establecida en el artículo 44 de la LCSP.

\section{Contrato de concesión de servicios}

Las causas específicas de resolución de este contrato están establecidas en el artículo 294 que suma a las propias del desaparecido contrato de gestión de servicio público, otras tomadas del contrato de concesión de obra pública. Entre las primeras se encuentran las recogidas en sus letras b), c), d) y e): «la demora superior a seis meses por parte de la Administración en la entrega al contratista de la contraprestación o de los medios auxiliares a que se obligó según el contrato»; «el rescate del servicio por la Administración» con la importante novedad, al igual que en el contrato de concesión de obra pública, de que se limita el uso de la figura para una "gestión directa por razones de interés público», con la obligación además de acreditar que dicha "gestión es más eficaz y eficiente que la concesional» ${ }^{47}$; «la supresión del servicio por razones de interés público» y la imposibilidad de su explotación «como consecuencia de acuerdos adoptados por la Administración con posterioridad al contrato» ${ }^{48}$. Entre las segundas, las recogidas en sus letras a) y f): «la ejecución hipotecaria declarada desierta o la imposibilidad de iniciar el procedimiento de ejecución hipotecaria por falta de interesados autorizados para ello en los casos en que así procediera, de acuerdo con lo establecido en la Ley» y «el secuestro o intervención de la concesión por un plazo superior al establecido de conformidad con el apartado 3 del artículo 263, sin que el contratista haya garantizado la asunción completa de sus obligaciones».

La regulación de los «efectos de la resolución» en el artículo 295 guarda un paralelismo claro con la dispuesta en el artículo 280 para el contrato de concesión de obras. Su apartado $1 .^{\circ}$ dispone que «en los supuestos de resolución por causa imputable a la Administración, esta abonará en todo caso al concesionario el importe de las inversiones realizadas por razón de la expropiación de terrenos, ejecución de obras de construcción y adquisición de bienes que sean necesarios para la explotación de la obra objeto de la concesión, atendiendo a su grado de amortización. Al efecto, se aplicará un criterio de amortización lineal». Llama la atención, no obstante, que aquí la Ley no determine, como si lo hace para la concesión de obra pública, el plazo, tres meses salvo que en el pliego se haya estipulado otro, en el que se ha de fijar «la cantidad resultante». Para los supuestos, de otra parte, en los que «la resolución obedezca a causas no imputables a la Administración», el artículo 295.1, en términos coincidentes con los del artículo 280.1 de la LCSP, establece que «el importe a abonar al concesionario por razón de la expropiación de terrenos, ejecución de obras y adquisición de bienes que deban revertir a la Administración será el que resulte de la valoración de la concesión, determinado conforme a lo dispuesto en el artículo $281 »$. Debe repararse, sin embargo, en que aquí la LCSP mantiene el elenco de conceptos procedentes del TRCSP que determinan la cantidad de abonar. No ha optado, a diferencia del 280.1, por una fórmula, «cualquiera de las causas posibles», susceptible de englobarlos a todos. El artículo 295.1 concluye con la delimitación de los supuestos en los que «se entenderá que no es imputable a la Administración la resolución del contrato», cuando «obedezca», son los mismos que para el contrato de concesión de obras, «a alguna de las causas previstas a), b), y f) del artículo 211, así como en las letras a) y f) del artículo $279 »$.

47 Previsión, ésta última, que se introduce por el Congreso de los Diputados a instancias, al igual que en el artículo 279.c), del Grupo Parlamentario Mixto (enmienda número 938).

48 Sobre esta causa de resolución pueden verse la Sentencia del Tribunal Supremo de 13 de mayo de 2015 (RJ $2015 / 3102$ ) o la Sentencia del Tribunal Superior de Justicia de Castilla y León, Sala de Valladolid de 22 de abril de 2015 (RJCA 2015/569). 
El artículo 295.2 determina, en los mismos términos en los que lo hacía el TRCSP, que «con independencia de lo dispuesto en el artículo 213, el incumplimiento por parte de la Administración o del contratista de las obligaciones del contrato producirá los efectos que según las disposiciones específicas del servicio puedan afectar a estos contratos». Sus apartados siguientes establecen reglas propias para algunas de las causas de resolución legalmente previstas. Así, y para «el supuesto de la letra b) del artículo 294», la demora en la entrega al concesionario de «la contraprestación o de los medios auxiliares» a que la Administración se obligó en el contrato, el apartado $3 .^{\circ}$ reproduce la norma del TRCSP que reconoce el derecho del contratista «al abono del interés de demora previsto en la Ley $3 / 2004$, de 29 de diciembre,... de las cantidades debidas o valores económicos convenidos, a partir del vencimiento del plazo previsto para su entrega y hasta la liquidación de la indemnización resultante de la resolución, así como de los daños y perjuicios sufridos», sin más novedad que la determinación del momento final al que se extiende el derecho del contratista al abono de esos intereses, «hasta la liquidación de la indemnización resultante de la resolución» ${ }^{49}$. Para los supuestos, en segundo lugar, «de las letras b), c), d) y e) del artículo 294, y en general en los casos en que la resolución del contrato se produjera por causas imputables a la Administración», el apartado $4 .^{\circ}$ dispone que «sin perjuicio de lo dispuesto en el apartado 1 de este artículo, la Administración indemnizará al contratista de los daños y perjuicios que se le irroguen, incluidos los beneficios futuros que deje de percibir» que se cuantificarán «conforme a lo establecido en la letra a) del apartado 3 del artículo 280 y a la pérdida del valor de las obras e instalaciones que no hayan de revertir a aquélla, habida cuenta de su grado de amortización».

\section{El contrato de suministro}

La LCSP mantiene en su artículo 306 las mismas causas de resolución del contrato de suministro que existían en el ordenamiento anterior. En primer término, letra a), «la suspensión de la iniciación del suministro por causa imputable a la Administración», a la que ahora, sin embargo, se añade expresamente "el desistimiento antes de la iniciación del suministro» y se rebaja el plazo de seis meses, previsto en el artículo 299.a) del TRCSP, a cuatro «a partir de la fecha señalada en el contrato para la entrega, salvo que en el pliego se señale otro menor». El contrato, en segundo lugar, podrá resolverse, letra b), por «desistimiento una vez iniciada la ejecución del suministro o la suspensión del suministro por un plazo superior a ocho meses acordada por la Administración, salvo que en el pliego se señale otro menor» ${ }^{50}$, previsión que reduce igualmente el más amplio de un año establecido en la disposición anterior.

En cuanto a los efectos de la resolución, el artículo 307.1 recoge la regla tradicional en nuestro ordenamiento según la cual «la resolución del contrato dará lugar a la recíproca devolución de los bienes y del importe de los pagos realizados, y, cuando no fuera posible o conveniente para la Administración, habrá de abonar ésta el precio de los efectivamente entregados y recibidos de conformidad». El apartado $2{ }^{\circ}$ del precepto, como también lo hacía el TRCSP, reconoce, para los supuestos de resolución previstos en la letra a) del artículo anterior, el derecho del contratista a percibir «una indemnización del 3 por 100 del precio de la adjudicación», aclarando, frente a lo dispuesto en la norma precedente, que dicha cantidad es «por todos los conceptos» y que en su cálculo ha de quedar excluido el IVA. Dos precisiones que mantiene el apartado $3 .^{\circ}$ aplicable a los supuestos de resolución del artículo 306.b) en los que el contratista tendrá derecho al «6 por 100 del precio de adjudicación del contrato de los suministros dejados de realizar en concepto de beneficio industrial, IVA excluido». El artículo, lo que no hacía la norma de la que procede, especifica que se entiende «por suministros dejados de realizar los que resulten de la diferencia entre los reflejados en el contrato primitivo y sus modificaciones aprobadas, y los que hasta la fecha de notificación del desistimiento o de la suspensión se hubieran realizado».

\section{Contrato de servicios}

El artículo 313.1 de la LCSP establece las mismas causas de resolución del contrato de servicios que ya existían en la legislación anterior con la incorporación expresa del desistimiento, junto a la suspensión.

49 Previsión que tiene su origen en la aceptación de las enmiendas número 408 del Grupo Parlamentario «Ciudadanos» y 731 del Grupo Parlamentario socialista, con el objeto, indicaba ésta última, de incorporar «una regulación paralela a la del contrato de concesión de obras...».

50 Sobre las notas básicas del desistimiento de la Administración en estos contratos puede verse la Sentencia del Tribunal Superior de Justicia de Madrid de 14 de abril de 2014 (JUR 2014/61398). 
También, y al igual que ocurre en el contrato de suministros, reduce los plazos de suspensión del contrato cuyo transcurso faculta al contratista para ejercer la potestad resolutoria. Son así causas específicas de resolución de este contrato «el desistimiento antes de iniciar la prestación del servicio o la suspensión por causa imputable al órgano de contratación de la iniciación del contrato por plazo superior a cuatro meses a partir de la fecha señalada en el mismo para su comienzo, salvo que en el pliego se señale otro menor» y «el desistimiento una vez iniciada la prestación del servicio o la suspensión del contrato por plazo superior a ocho meses acordada por la Administración, salvo que en el pliego se señale otro menor». La LCSP mantiene igualmente, en la letra c), que «los contratos complementarios quedarán resueltos, en todo caso, cuando se resuelva el contrato principal».

El propio artículo 313 determina en su apartado $2 .{ }^{\circ}$ los efectos de la resolución de estos contratos. Dará «derecho al contratista, en todo caso, a percibir el precio de los estudios, informes, proyectos, trabajos o servicios que efectivamente hubiese realizado con arreglo al contrato y que hubiesen sido recibidos por la Administración». Una previsión que el apartado $3 .^{\circ}$, para «los supuestos de resolución previstos en las letras a) y c)» del apartado $1 . .^{\circ}$, completa con el reconocimiento del derecho del contratista «a percibir, por todos los conceptos, una indemnización del 3 por 100 del precio de adjudicación del contrato, IVA excluido». En los supuestos de resolución de la letra b), el derecho alcanzará, «por todos los conceptos» igualmente, al «6 por 100 del precio de adjudicación del contrato de los servicios dejados de prestar en concepto de beneficio industrial, IVA excluido, entendiéndose por servicios dejados de prestar los que resulten de la diferencia entre los reflejados en el contrato primitivo y sus modificaciones aprobadas, y los que hasta la fecha de notificación del desistimiento o de la suspensión se hubieran prestado». La LCSP ofrece aquí, en su comparación con la regulación precedente, algunos cambios de interés. Así y junto a una rebaja en la cuantía de esas indemnizaciones que pasan del 5 y 10 por ciento, al 3 y 6 respectivamente y la especificación de que en su cómputo queda excluido el IVA, cabe destacar el reconocimiento de este derecho en los supuestos de resolución de los contratos complementarios, así como la sustitución del listado de conceptos del artículo 309.3 del TRCSP, «los estudios, informes, proyectos o trabajos pendientes de realizar» por una fórmula comprensiva de estos y otros posibles, «por todos los conceptos». 